\title{
Fusarium solani induces the formation of agarwood in Gyrinops versteegii (Gilg.) Domke branches
}

\author{
Ahmad Faizal $^{1} \cdot$ Alda Wydia Prihartini Azar $^{1} \cdot$ Maman Turjaman $^{2} \cdot$ Rizkita Rachmi Esyanti $^{1}$
}

Received: 1 November 2019 / Accepted: 6 April 2020 / Published online: 18 April 2020

(C) The Author(s) 2020

\begin{abstract}
Agarwood is a resinous wood produced by some members of plant family Thymelaeaceae under certain conditions. Agarwood is highly prized, but its formation requires a long-time process in nature. Therefore, various induction techniques have been explored to hasten the process. In this study, we induced agarwood in Gyrinops versteegii, one of the most abundant agarwood-producing trees in Indonesia. We used 12 trees and wounded four branches on each tree through an injection process. We used two strains of the endophytic fungi Fusarium solani isolated from Gorontalo and Jambi Provinces. After 3 months, the inoculated wood had an extensive resinous zone, when compared to wounded control wood. Gas chromatographic-mass spectrometric analysis of the inoculated samples revealed the presence of several sesquiterpenes characteristic of agarwood. These included alloaromadendrene, $\beta$-eudesmol and $\beta$-selinene as well as the chromone derivatives 2-(2-phenylethyl) chromen-4-one, 6-methoxy-2-(2-phenylethyl) chromen-4-one, and 6,7-dimethoxy-2-(2-phenylethyl) chromen-4-one. We conclude that this method successfully induced agarwood to form in a matter of months and could be used to enhance the success of agarwood cultivation.
\end{abstract}

Keywords Agarwood $\cdot$ Bioinduction $\cdot$ Fusarium solani $\cdot$ Gyrinops versteegii

\section{Introduction}

Agarwood is formed in the wood of trees of the Thymelaeaceae in response to infection by microbes. The wood is dark and contains fragrant resins produced by secondary metabolism. Agarwood is used as incense and its resins are used as essential oils, in perfumes, in cosmetics, and in drugs (Turjaman et al. 2016; Wang et al. 2018). A variety of names have been applied to this fragrant wood, including "jinkoh" (Japan), "oudh" (Arabic), "eaglewood" (Papua New Guinea), and "agar" (India) (Naziz et al. 2019; Rasool and Mohamed 2016). The formation of agarwood is a complex process that can sometimes require as long as

Ahmad Faizal

afaizal@sith.itb.ac.id

1 Plant Science and Biotechnology Research Group, School of Life Sciences and Technology, Institut Teknologi Bandung, Jalan Ganeca 10, Bandung 40132, Indonesia

2 Forest Microbiology Research Group, R\&D Centre for Forest, Environment \& Forestry Research, Development, and Innovation Agency (FORDA), Ministry of Environment and Forestry, Jl. Gunung Batu 5, Bogor 16680, Indonesia
100 years, in the wild (Turjaman et al. 2016). Agarwood formation is initiated when the tree is wounded. The area of wood that is wounded can be identified by its color, which is usually darker than that of unwounded trees. It is believed that the wound, when infected by microbes (Rasool and Mohamed 2016; Turjaman et al. 2016), triggers the plant's self-defense mechanisms. These include the accumulation of secondary metabolites, with their unique and highly prized fragrance. The high economic value of agarwood has led to overharvesting of the wood, threatening the trees in their natural habitat. Therefore, agarwood producing-species such as Aquilaria spp. and Gyrinops spp. have been listed on Appendix II by the Convention of International Trade in Endangered Species of Wild Fauna and Flora (http://checklist.cites.org).

The long period associated with agarwood formation has, predictably, led to attempts to accelerate its production. Techniques based on physical and mechanical wounding, or on chemical and biological agents have been tested (Azren et al. 2019). The physical or mechanical manipulations have usually been performed by wounding, boring, or nailing, but agarwood formation in response to these treatments still takes a long time and was of poor quality (Liu et al. 2013). Chemical agents, 
such as jasmonic acid (Xu et al. 2016), methyl jasmonate, salicylic acid (Okudera and Ito 2009), sulphuric acid (Thanh et al. 2015), and hydrogen peroxide ( $\mathrm{Lv}$ et al. 2019) have also been tried. These treatments did induce agarwood formation in a relatively shorter time than in the wild but there are environmental concerns about their use (Turjaman et al. 2016). This has led researchers to focus on biological induction. They have employed endophytic fungi of which several appear to be important in agarwood formation, including Aspergilus niger (Subasinghe et al. 2019), Fusarium spp. (Mohamed et al. 2010; Sen et al. 2017; Subasinghe et al. 2019; Tian et al. 2013), Lasiodiplodia theobromae (Chen et al. 2017), and Rigidoporus vinctus (Chen et al. 2018). The role of F. solani in agarwood formation has been extensively studied in Indonesia, especially in the genus Aquilaria (Faizal et al. 2017; Nasution et al. 2019).

There are 26 species of agarwood-producing trees in Indonesia, mostly in the genera Aetoxylon, Aquilaria, Enkleia, Gonystylus, Gyrinops, Phaleria and Wikstroemia genera (Susilo et al. 2014). Aquilaria and Gyrinops are the dominant agarwood-producing trees in Indonesia as well as in other regions in Southeast Asia, including Malaysia, Vietnam, Cambodia, and Thailand (Sitepu et al. 2011). In Indonesia, these species are abundant in Sumatra, Kalimantan, Sulawesi, and the Papua islands (Komar et al. 2014).

Currently there are 6 species of Aquilaria spp. found in Indonesia. A. malaccensis, A. beccariana, A. microcarpa, A. cumingiana, and $A$. hirta, which are found in Kalimantan and/or Sumatra, and A. filaria occurs in Papua and Maluku (Mulyaningsih and Yamada 2018). Furthermore, there are 7 species of Gyrinops spp. found in Indonesia. G. caudata, G. ledermannii, G. podocarpus, and G. salicifolia (in Papua), G. decipiens (in Sulawesi), G. moluccana (in Maluku), and G. versteegii (in Sulawesi, Papua, and Nusa Tenggara islands (Susilo et al. 2014). To date, most studies have focused on Aquilaria species. Researchers have isolated the endophytic fungi present, optimized induction, and analyzed the chemical constituents in the agarwood (Chen et al. 2017; Faizal et al. 2017; Nasution et al. 2019; Premalatha and Kalra 2013; Sen et al. 2017).

There are fewer studies of species of the genus Gyrinops, but G. salicifolia (Shao et al. 2016) and G. wala (Subasinghe et al. 2019) have been shown to produce sesquiterpenes. Less in known about $G$. versteegii, although it is the most cultivated Gyrinops species in Indonesia. This led us to examine agarwood formation in G. versteegii. We approached this study by using F. solani to induce agarwood. We were particularly interested in determining if the induction would hasten the formation of agarwood in G. versteegii.

\section{Material and methods}

\subsection{Fungal material and inoculation}

We used two different strains of F. solani: strain Gorontalo (GSL1) and strain Jambi (GSL2), as inoculants. These had been isolated previously by Forestry Research and Development Agency (FORDA). The fungal colony was grown on potato dextrose broth (PDB) medium for 14 days prior to inoculation (Faizal et al. 2017).

Twelve trees were used in this experiment. Four branches on each tree were inoculated as follows. About 10 wounds per branch were made with DeWalt ${ }^{\circ}$ bore injector. Wounds were no deeper than half the diameter of the branch and were approximately $10 \mathrm{~cm}$ apart. Each tree received only one treatment. Treatments were (1) no wounding or injection (healthy control plants), (2) wounded and injection with PDB medium (wounded control plants), (3) wounded and injected with F. solani strain Gorontalo (GSL1) in PDB media, (4) wounded and injected with strain Jambi (GSL2) in PDB media. Three $\mathrm{mL}$ of inoculant (GSL1 or GSL2) or PDB medium were injected into each hole on each branch. Each of the four treatments, except treatment one, involved three injections done simultaneously a few minutes apart to prevent excessive inoculant. All injections were conducted at the same time and each injection involved $1 \mathrm{~mL}$ inoculant or PDB medium into each hole. The holes were left open after injection.

\subsection{Plant material and growth conditions}

The $G$. versteegii trees used in this study had been cultivated in the field for 15 years in Bogor, Indonesia at $560 \mathrm{~m}$ above sea level $\left(6^{\circ} 39^{\prime} 07.42^{\prime \prime} \mathrm{S}\right.$ to $6^{\circ} 39^{\prime} 09.70^{\prime \prime} \mathrm{S}$ and $106^{\circ} 44^{\prime} 51.61^{\prime \prime}$ $\mathrm{E}$ to $106^{\circ} 44^{\prime} 53.06^{\prime \prime} \mathrm{E}$ ). We used tree branches with $12.5 \mathrm{~cm}$ circumference. Two of four branches from each tree were harvested 3 and 6 months after the start of the experiment and directly prepared for subsequent analyses.

The resin and non-resinous parts of the woods were separated and weighed. Subsequently, they were chopped into wood chips and subjected to anatomical study and olfactory tests. The rest of the chips were ground into powder for more olfactory tests and extraction for chemical analysis.

\subsection{Wood anatomy observation}

Wood chips were immersed and boiled for $2 \mathrm{~h}$ in glycerin:ethanol:aquadest (3:1:1); boiling softens the wood (Faizal et al. 2017). The sections made from wood chips were mounted on microscopic slides and observed under a light microscope (Nikon Eclipse E800). The resinous interxylary phloem was detected with neutral red. 


\subsection{Olfactory test}

Human participants who responded to a request to participate in this study were recruited. A total of 34 students and faculty members from our university were randomly selected and exposed to either burned as for incense purpose or powdered wood of three and 6 months harvested samples. The respondents were asked to score the intensity level of agarwood aroma on a scale from 1 to 5 , with 5 being the most intense. A rating of 5 indicated the most intense fragrance and a rating of 1 the least intense. The data was displayed as a radar chart type and the significance level of the data was performed by statistical analysis.

\subsection{Sample extraction and chemical analysis}

The developed resinous woods were extracted and the chemicals in the extract were analyzed. Resinous agarwood of each branch on each tree was pooled and $1 \mathrm{~g}$ of powdered agarwood was extracted in $30 \mathrm{~mL}$ of methanol or ethyl acetate and incubated for 3 days on a rotary shaker, centrifuged for $10 \mathrm{~min}$ at $1000 \mathrm{rpm}$, and the supernatant collected for gas chromatographic-mass spectrophotometric (GC-MS) analysis. GC-MS analysis was conducted using an Agilent 6890 GC model number Agilent 19091S-433 with a capillary column HP-5MS, $0.25 \mathrm{~mm} \times 30 \mathrm{~m} \times 0.25 \mathrm{um}$. The relative amount $(\%)$ of each component was calculated by comparing its average peak area to the total areas. The resulting chromatograms were integrated and aligned according to their groups. Identification of the compounds was based on the comparison of the calculation of their retention time and authentic mass spectra data with the existing Wiley MS libraries.

\subsection{Statistical analysis}

Data were analyzed using one-way ANOVA and the comparison of the mean from each result was contrasted using Duncan's multiple range test. All statistical analyses were performed at the level of $P$ value less than 0.05 using an IBM SPSS Statistics 20 Package. The results from GC-MS were identified and displayed as a heat map and principal component analysis (PCA) graph with the online software MetaboAnalyst 4.0 (https://www.metaboanalyst.ca). The relative concentration of chemical compounds, expressed as $\%$ peak area, was used for analyzing the differences between samples. Pearson was used as a distance measurement of clustering for heatmap. Principal components analysis was performed in 2-D scores plot.

\section{Results}

\subsection{Development of resinous zones in G. versteegii}

The development of a resinous zone a month after wounding, and the much larger resinous zone when the wounding was accompanied by inoculation with either $F$. solani GSL1 or GSL2 is shown in Fig. 1. This resinous zone continued to expand during the 3- to 6-months period of the experiment (Fig. 2a), compared to wounded only (Fig. 2b). After 6 months, the resinous zone not only surrounded the wound, but covered most of the branch and extended deep into the wood. The fraction of resinous wood amounted to $35 \%$ of the total weight of each harvested branch from two different trees and there was no significant difference between the two strains of $F$. solani.

\subsection{Microscopic analysis of resinous wood in $G$. versteegii}

When we observed cross sections of G. versteegii wood, we detected interxylary phloem, a unique structure (Fig. 3). This interxylary phloem is believed to be essential for the accumulation of resins in agarwood (Liu et al. 2019). The presence of sesquiterpenes in the wood was also shown by staining with neutral red. The dark red coloration indicates the presence of sesquiterpenes, typically associated with interxylary phloem or xylem ray parenchyma. The micrographs show that there was essentially no dark red color in the healthy tissue (Fig. $3 a)$, while the staining in the wood, that had only been wounded, was not as intense as in the inoculated wood (Fig. 3b). The inoculated samples had intense staining, evidence for an abundance of terpenes in the interxylary phloem and the xylem rays (Figs. 3c and d).

\subsection{Olfactory test}

Agarwood is well known by its unique fragrance and its quality can be assessed by the level of fragrance. The results of the olfactory tests of the wood, using human subjects are shown in Fig. 4. Samples were presented to participants either powdered or after burning. There was no significant difference in the level of fragrance of wood 3 or 6 months after treatment.

For the powdered samples, the level of fragrance of wood that had been inoculated was significantly greater than that of the wood that had been wounded only. There was no significant difference in fragrance level with respect to the strains of $F$. solani used, both for powdered and burned samples. Wood inoculated with both strains of $F$. solani had fragrance levels between 3 and 4 , while the wood that had been wounded only earned a rating of $2-3$. In contrast, participants rated the burned samples significantly more fragrant than the powdered samples $(P \leq 0.05)$. 
Fig. 1 Photographs of branches of $G$. versteegii 4 weeks after the plants had been wounded or wounded and inoculated with F. solani (either strain GSL1 or GSL2). Note the resinous zones that developed around the wounds of the inoculated plants
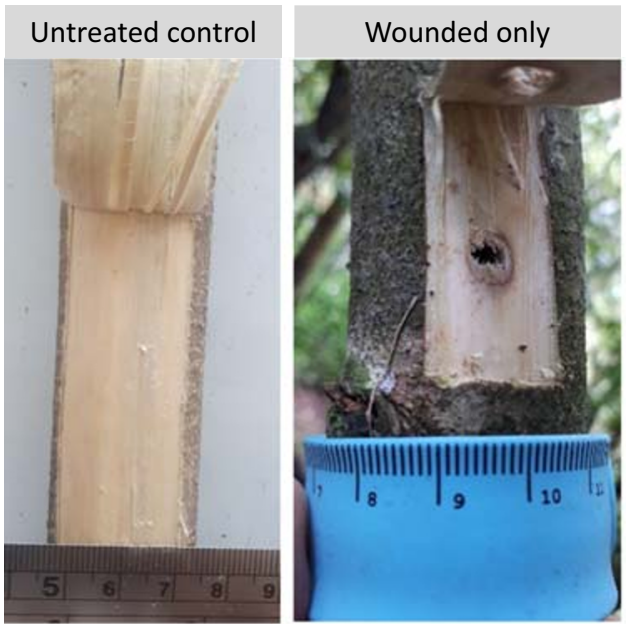

GSL1-inoculated

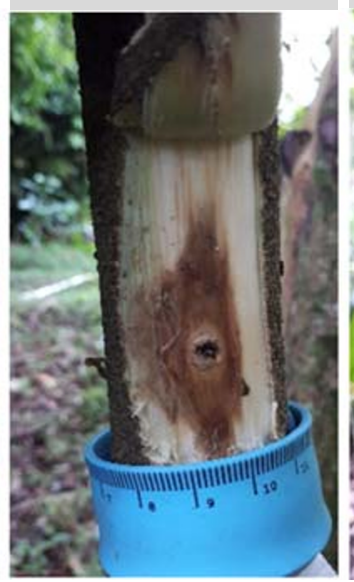

GSL2-inoculated

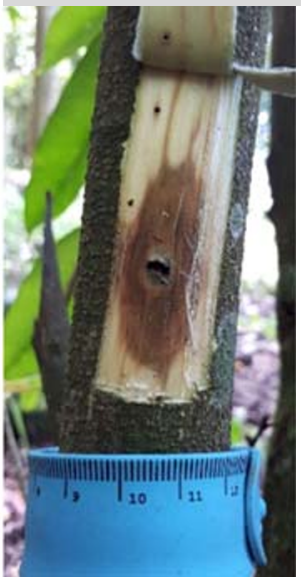

\subsection{Chemical constituents of agarwood in G. versteegii}

The results of the chemical analyses are displayed in Figs. 5 and 6. Several chromones and sesquiterpenes were present in methanol extracts (Fig. 5a), while fatty acids and related compounds were detected in the ethyl acetate extracts, which had no chromones or sesquiterpenes (Fig. 5b). Phenolic compounds were present in both extracts. We also detected aldehydes, benzene and benzopyran derivatives, carboxylic acids, polycyclic aromatic hydrocarbons, heterocyclic compounds, and phytosterols.

The abundance of each compound varied in different samples. Several compounds were detected in almost every sample. Some compounds were only present in the healthy control, and others were only present in treated samples. For example, trans- sinapyl alcohol and 4-[(E)-3-hydroxyprop-1-enyl]-2methoxyphenol were detected in methanol extracts of all samples, while hexadecanamide was found in ethyl acetate extracts of almost all wood samples. In contrast, 2,4-ditert-buthylphenol was only detected in ethyl acetate extract of wood 6 months after it had been treated. Furthermore, five chromones derivatives and 16 sesquiterpenes were detected from methanol extracts. Five-hydroxy-7-methoxy-2-(3-methoxyphenyl) chromen-4-one was detected in all samples including healthy plants. Four of the chromones we detected, including 2-(2phenylethyl) chromen-4-one, 6-methoxy-2-(2-phenylethyl) chromen-4-one, 6,7-dimethoxy-2-(2-phenylethyl) chromen-4one, and 5-hydroxy-2-(4-hydroxyphenyl)-7-methoxychromen4-one were present in wood samples that had been wounded only and in wood that had been wounded and inoculated, but
Fig. 2 A branch of $G$. versteegii 6 months after it was wounded and inoculated with $F$. solani (a) compared with wounded only (b). Note that the resinous zone has expanded to much of the surface area and deep into the wood after it was inoculated with $F$. solani as long as 10 sites of injected holes (indicated by black arrows). In contrast with wounded only sample, the resinous was only developed at injection site (indicated by red arrows)
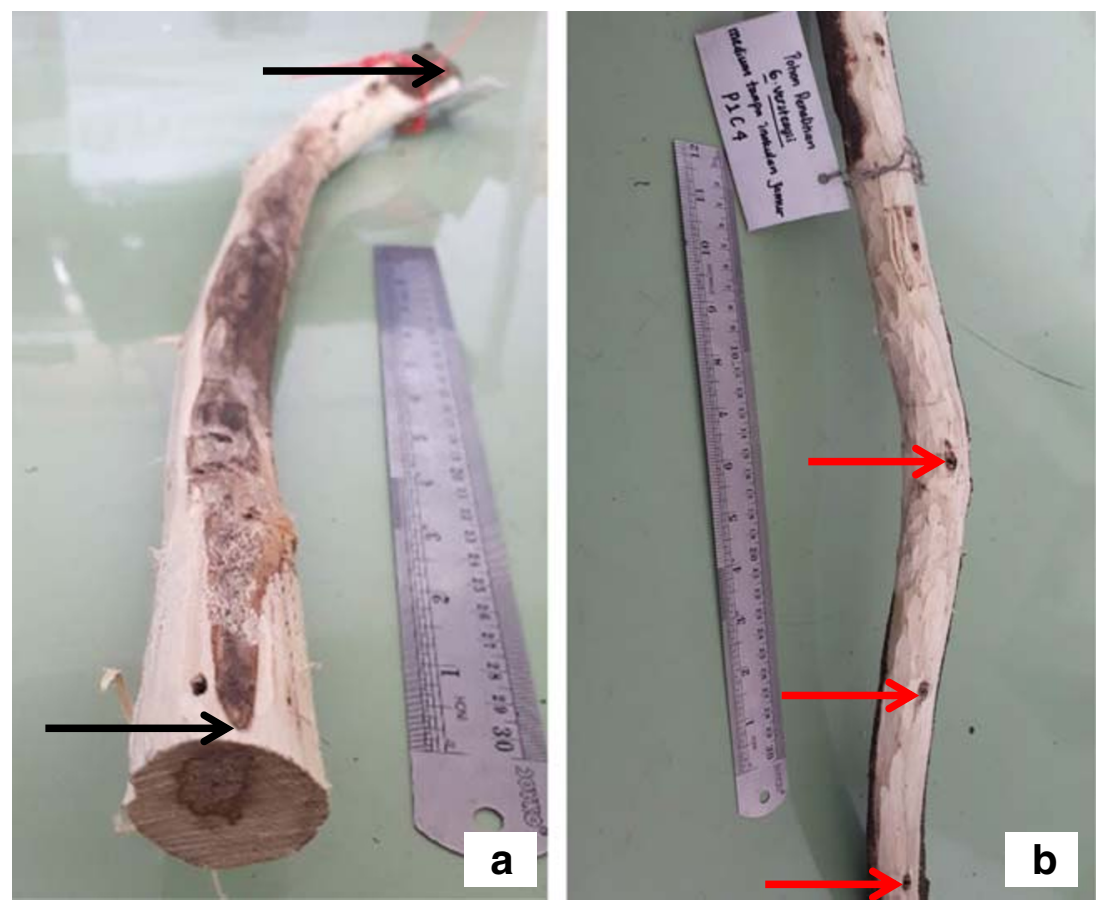
Fig. 3 Micrographs of transverse sections of wood tissue from branches of $G$. versteegii 6 months after treatment and stained with neutral red for sesquiterpenes. a healthy, unwounded tissue; $\mathbf{b}$ wounded tissue; $\mathbf{c}$ wounded tissue inoculated with F. solani GSL1, and $\mathbf{d}$ wounded tissue inoculated with $F$. solani GSL2. (IP, interxylary phloem; XR, xylem ray parenchyma)
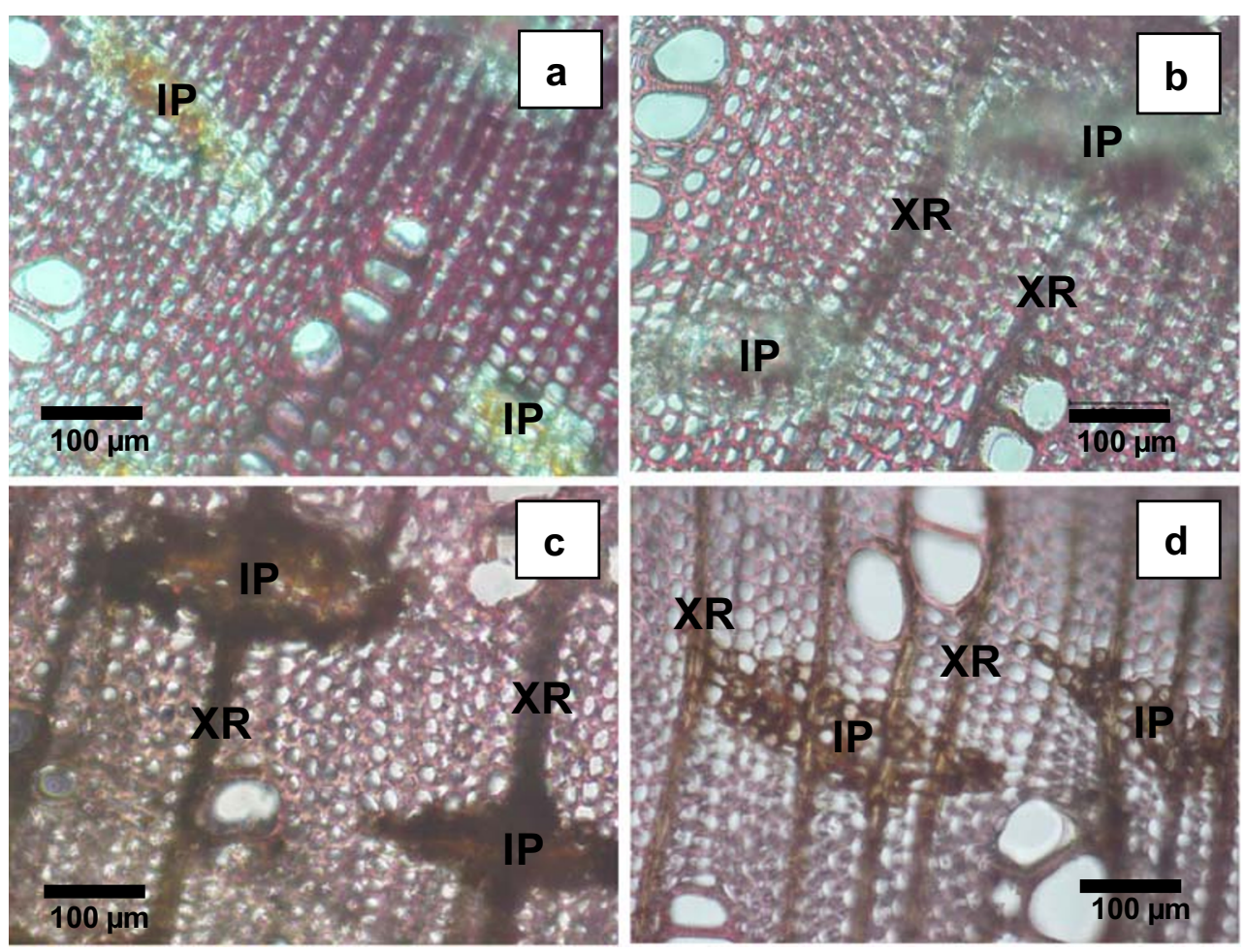

not in untreated control. The following sesquiterpenes were only present in wood samples that had been wounded and inoculated: $\alpha$-selinene, $\beta$-selinen, $\beta$-eudesmol, eudesma-4,6-diene, $\gamma$-gurjunene, valerenol, valerenic acid, iso-isovelleral, vulgarol B, caparratriene, aromandendrene, alloaromadendrene, 10s,11s-himachala-3(12) 4-diene, 1,1,4,7tetramethyl-1a,2,3,5,6,7,7a,7b-octahydrocyclopropa[e]azulene, 4a,5-dimethyl-3-prop-1-en-2-yl-2,3,4,5,6,7-hexahydro-1H- naphthalene, and cis-Z- $\alpha$-bisabolene epoxide. Aromadendrene was present in samples from branches that had been wounded.

The GC-MS analysis did not detect any sesquiterpenes in samples from untreated control. These results are consistent with our microscopic analysis (Fig. 3a). We concluded that wood from branches inoculated with strains of $F$. solani accumulated more terpenes than wood from branches that had been wounded only, while the healthy wood had essentially no sesquiterpenes.
Fig. 4 Results from an olfactory test of wood samples of G. versteegii. Samples were taken at 3 and 6 months after treatment. Thirty-four people participants evaluated the level of fragrance intensity of the wood. (Participants rated the fragrance based on the following scale: 1 nearly odorless, 2 little odor, 3 fair odor, 4 strong odor, 5 very strong and pleasant odor)

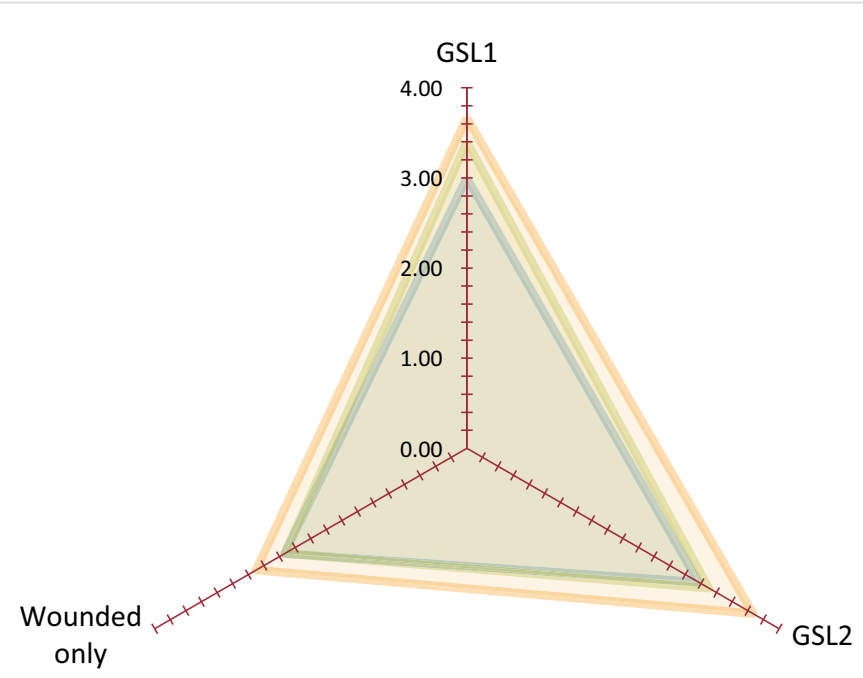

Powdered samples 3 months Powdered samples 6 months Burned samples 6 months 
Fig. 5 Heat map showing relative content of likely compounds in extracts of wood samples from branches of $G$. versteegii. Samples were taken at 3 and 6 months after treatment using either methanol extracts (a) or ethyl acetate extracts (b). Highest percentage area of the compounds is shown as dark-red colour, while lowest percentage area of the compounds is shown as blue colour. (Key: UC, healthy, untreated control; GSL1, samples from wood that had been wounded and inoculated with $F$. solani GSL1; GSL2, samples from wood that had been wounded and inoculated with $F$. solani GSL2; W, wood from trees that had been wounded only; 3 , samples treated for 3 months; 6 , samples treated for 6 months) a

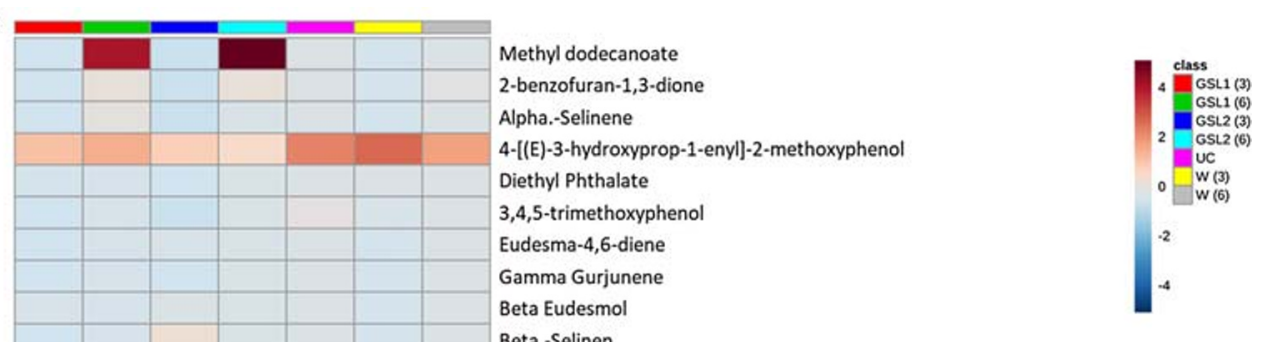

Beta.-Selinen

1,1,4,7-tetramethyl-1a,2,3,5,6,7,7a,7b-octahydrocyclopropa[e]azulene Valerenol

Valerenic acid

Trans-sinapyl alcohol

Cis-Z-.alpha.-Bisabolene epoxide

VULGAROL B

Caparratriene

Aromandendrene

Alloaromadendrene

iso-isovelleral

10s,11s-Himachala-3(12),4-diene

4a,5-dimethyl-3-prop-1-en-2-yl-2,3,4,5,6,7-hexahydro-1H-naphthalene

2-(2-phenylethyl)chromen-4-one

6-methoxy-2-(2-phenylethyl)chromen-4-one

2H-1-Benzopyran-2-one-4-diethylphosphonate

5-hydroxy-7-methoxy-2-(3-methoxyphenyl)chromen-4-one

Glysobuzole

6,7-dimethoxy-2-(2-phenylethyl)chromen-4-one

5-hydroxy-2-(4-hydroxyphenyl)-7-methoxychromen-4-one

Stigmast-5-en-3-ol, (3.beta.,24S)-(CAS)

\section{b}

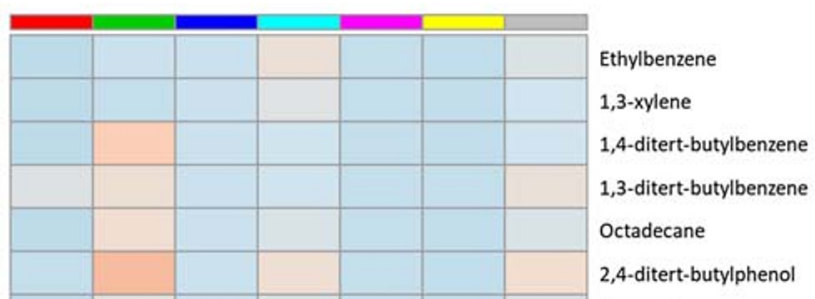

Docos-1-ene

1-(2,6,6-trimethylcyclohex-2-en-1-yl)pent-1-en-3-one

(2E)-2-benzylideneheptanal

1-(1,1,2,3,3,6-hexamethyl-2H-inden-5-yl)ethanone

2-benzylideneoctanal

1-(2,6,6,8-tetramethyl-9-tricyclo[5.3.1.01,5] undec-8-enyl)ethanone

Methyl hexadecanoate

9-Octadecenamide, (Z)- (CAS)

1-(4-tert-butyl-2,6-dimethyl-3,5-dinitrophenyl)ethanone

Hexadecanamide

Sesquiterpenes and chromones were only found in wood samples from branches that had been wounded. The PCA also shows that the wounded, inoculated plants had a specific range compared to the wounded only plants and the untreated control either in methanol extracts (Fig. 6a) or in ethyl acetate extracts (Fig. 6b). This specific range is a result of chemical constituents in the inoculated samples that were not present in the uninoculated plant samples. Based on these results, it is clear that inoculation plays an important role in agarwood formation. 


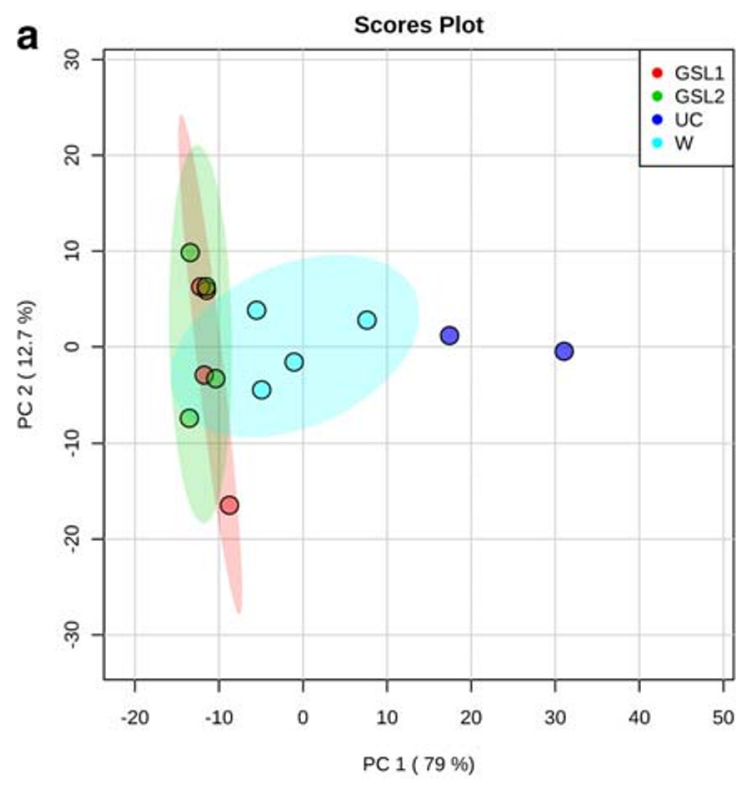

Fig. 6 Principal component analysis of the chemical contents of wood samples of G. versteegii. GC-MS results derived from 3- and 6-month samples after treatment were pooled using either methanol extracts (a) or ethyl acetate extracts (b). (Key: UC, healthy, untreated control; GSL1,

\section{Discussion}

Agarwood is formed when an agarwood-producing tree is wounded and this causes a resinous zone to form around the wound (Rasool and Mohamed 2016). In this study, we were able to induce a considerable amount of agarwood formation by inoculating wounds with the endophytic fungus $F$. solani. Agarwood has also been successfully induced in A. sinensis upon inoculation with Rigidoporus vinctus (Chen et al. 2018). They observed that, after inoculation, the wood became black with an agarwood-like dark line. They considered that the resinous zone was formed as part of the defense response in agarwood-producing trees. They also believed that infection by fungi may lead to lignin degradation, part of the defense response. However, wounding and fungal inoculation appear not to have identical effects with respect to agarwood formation and chemical constituents.

Generally, fungi are effective inducers of agarwood resinous formation (Rasool and Mohamed 2016). F. solani is highly virulent in Aquilaria, and thus might be expected to be quite effective in agarwood induction (Faizal et al. 2017; Turjaman et al. 2016). F. solani successfully induced agarwood formation in A. microcarpa, A. crassna, and A. beccariana within 75 days of inoculation (Santoso et al. 2011). In A. malaccensis, the resinous zone was apparent at the first week after inoculation with the fungus (Faizal et al. 2017).

There are several genera of fungi which known to have the potential to induce agarwood formation in agarwood-producing trees. These include Aspergillus, Arthrinium, Botryosphaeria, Chaetomium, Colletotrichum, Cylindrocladium, Diaporthe,

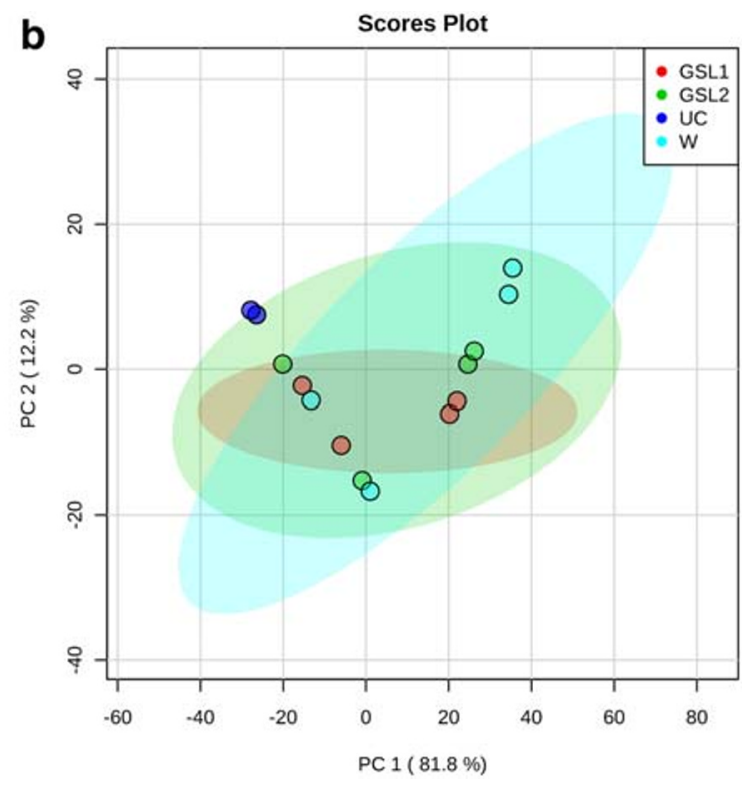

samples from wood that had been wounded and inoculated with $F$. solani GSL1; GSL2, samples from wood that had been wounded and inoculated with $F$. solani GSL2; W, wood from trees that had been wounded only). Bullets showed the replicates of each treatment

Fusarium, Lasiodiplodia, Penicillium, Pestalotiopsis, Rhizopus, Rigidoporus, Trichoderma, and Xylaria (Al-Hindi et al. 2018; Chen et al. 2017; Cui et al. 2013; Faizal et al. 2017; Monggoot et al. 2017; Sen et al. 2017; Subasinghe et al. 2019; Tamuli et al. 2005; Tian et al. 2013). For example, Fusarium and Aspergillus are two genera of fungi abundantly found in $G$. walla. Inoculation with $F$. solani and A. niger in $G$. walla resulted in a similar content of agarwood chemical constituents. Interestingly, the re-isolation of fungi from the inoculated samples showed that only A. niger and $F$. solani grew from resinous tissues (Subasinghe et al. 2019). This indicated that both of these endophytes support agarwood formation and may suppress the growth of other microbes.

Agarwood induction as a result of infection by fungi is expected to be accompanied by the chemical components that are typically present, for example, sesquiterpenes. Understanding the plant's stress mechanism allows a connection to be made between the defense response and accumulation of the compounds that confer agarwood's prized qualities. Upon infection, fungi release chemical signals called elicitors that the plant recognizes (Henry et al. 2012). Recognition initiates a signaling process through a phosphorylation cascade in the plant's plasma membrane, involving cyclic adenosine monophosphate (cAMP) and mitogen-activated protein kinase (MAPK), known as the MAPK signaling pathway. It has an important role in the plant's response to pathogen attacks (Pitzschke et al. 2009). Sesquiterpenes, one of the chemical constituents of agarwood, is produced by the MAPK signaling pathway (Rasool and Mohamed 2016; Xu et al. 2013). 
From the results of the olfactory test, we conclude that the level of fragrance of agarwood induced by fungal infection was greater than that of agarwood induced by wounding only, and that burned wood was more fragrant than powdered samples. We conclude that agarwood is composed by volatile or semi-volatile compounds, in agreement with others (Cui et al. 2013; Naef 2011). Generally, the chemical constituents of agarwood had little odor at room temperature but longlasting fragrance when the wood was burned. Some of the chemical constituents of agarwood appear to be agarofurans, agarol, eudesmanes, selinanes, valencanes, eremophilanes, guaianes, preziznes (jinkohol), vetispranes (agarospirol), 2-(2-phenylethyl)-chromones, 5,6,7,8-tetrahydro-2-(2phenylethyl)-chromones, and diepoxy-tetrahydro-2-(2phenylethyl)-chromones (Naef 2011). Phenols and other aromatic compounds have also been detected in agarwood which are important in plant defense mechanisms (Chhipa et al. 2017; Novriyanti and Santosa 2011). In addition, we also detected stigmasterol in the methanol extracts, which is also an agarwood constituent and one of the major steroids in agarwood (Liao et al. 2018).

Several workers reported that chromones and sesquiterpenes were the main agarwood constituents (Chen et al. 2018; Cui et al. 2013; Nasution et al. 2019). Generally, chromones and sesquiterpenes have a high polarity index and should be easily extracted into polar solvents such as methanol, ethanol, or acetone (Naef 2011). GC-MS analysis of our methanol extracts revealed several chromones and sesquiterpenes in our samples, but none in the ethyl acetate extract. This result confirms that the main agarwood constituents are polar. Four of five chromones compound that we detected were present only in wood that had been wounded (with or without inoculation).

Two sesquiterpenes present in agarwood, specifically alloaromadendrene and aromadendrene, are also used to distinguish agarwood quality (Pasaribu et al. 2015). In our study, aromadendrene was present in all samples that had been wounded, (with or without fungal inoculation), whereas alloaromadendrene was present only in wood that had been inoculated. From these results, we conclude that wounding is the primary factor in agarwood formation, in agreement with others (Xu et al. 2013). Physical stress, whether wounding or pathogen attack, will activate the signal transmission pathway that leads to activation of the transcription factor that regulates sesquiterpene synthase (Tan et al. 2019). Wound or damage in agarwood-producing trees leads to pathogenic microbe invasion around the wound, which will elicit the defense mechanism that subsequently leads to initiation of agarwood formation. This may explain why sesquiterpenes are detected in wounded wood, regardless of fungal inoculation, but not in healthy, untreated control. Aromadendrene was the only sesquiterpene present in wood that had been wounded. Because we detected additional sesquiterpenes in fungal-inoculated samples, we speculate that the inoculation and infection are important components in agarwood formation. Wounding may be the first trigger of agarwood formation, but the plant's response to infection by a pathogen is intense.

The injection technique we used in this study has been used before to induce agarwood production (Chhipa et al. 2017). With this method, it is possible to combine the necessary wounding with inoculation with endophytic microbes. Combining these two steps results in agarwood formation within a short time. The dosage of fungal inoculant was based on the depth of the holes and the circumferences of the branches. A higher dose of fungal inoculants might have induced a greater or faster agarwood formation, but an excess could have flowed out of the holes.

Inoculation in branches for 6 months did not result in the widespread agarwood formation in main stem. Thus, it would be best if inoculation was done on branches and communities should limit harvest to the branches for a more sustainable production. Our current induction technique could be extended to increase the resinous portion of the branches. G. versteegii naturally develops many branches (Susilo et al. 2014) and these could be inoculated. Furthermore, harvesting just the branches will stimulate the release of axillary buds to form new branches due to its auxin redistribution (Rameau et al. 2015). Finally, light intensity in tropical regions is also a critical factor for promoting bud outgrowth and shoot elongation in tree species such as $G$. versteegii.

Acknowledgments The authors acknowledge FORDA for its help in fungal inoculation and Mr. Ramzi Salim for his permission to conduct this research in his experimental field. This research was partially funded by the Ministry of Research, and Technology, Republic of Indonesia through competitive grant under the scheme of World Class Research (contract number: 096/SP2H/LT/DRPM/2020) awarded to A.F.

Authors' contributions A.F., A.W.P.A, and M.T. designed the study, developed the methodology, performed the experiment, analyzed the data, and wrote the manuscript. R.R.E. analyzed the data and wrote the manuscript.

\section{Compliance with ethical standards}

Conflict of interest The authors declare no conflict of interest. The financial supporter had no role in the design of study, perform the experiment and in the decision to publish the results.

Open Access This article is licensed under a Creative Commons Attribution 4.0 International License, which permits use, sharing, adaptation, distribution and reproduction in any medium or format, as long as you give appropriate credit to the original author(s) and the source, provide a link to the Creative Commons licence, and indicate if changes were made. The images or other third party material in this article are included in the article's Creative Commons licence, unless indicated otherwise in a credit line to the material. If material is not included in the article's Creative Commons licence and your intended use is not permitted by statutory regulation or exceeds the permitted use, you will need to obtain permission directly from the copyright holder. To view a copy of this licence, visit http://creativecommons.org/licenses/by/4.0/. 


\section{References}

Al-Hindi RR, Aly SE, Hathout AS, Alharbi MG, Al-Masaudi S, Al-Jaouni SK, Harakeh SM (2018) Isolation and molecular characterization of mycotoxigenic fungi in agarwood. Saudi J Biol Sci 25:1781-1787

Azren PD, Lee SY, Emang D, Mohamed R (2019) History and perspectives of induction technology for agarwood production from cultivated Aquilaria in Asia: a review. J Forest Res 30:1-11

Chen X, Sui C, Liu Y, Yang Y, Liu P, Zhang Z, Wei J (2017) Agarwood formation induced by fermentation liquid of Lasiodiplodia theobromae, the dominating fungus in wounded wood of Aquilaria sinensis. Curr Microbiol 74:460-468

Chen X, Liu Y, Yang Y, Feng J, Liu P, Sui C, Wei J (2018) Trunk surface agarwood-inducing technique with Rigidoporus vinctus: an efficient novel method for agarwood production. PLoS One 13:e0198111

Chhipa H, Chowdhary K, Kaushik N (2017) Artificial production of agarwood oil in Aquilaria sp. by fungi: a review. Phytochem Rev $16: 835-860$

Cui J, Guo S, Fu S, Xiao P, Wang M (2013) Effects of inoculating fungi on agilawood formation in Aquilaria sinensis Chinese. Sci Bull 58: 3280-3287

Faizal A, Esyanti RR, Aulianisa EN, Iriawati, Santoso E, Turjaman M (2017) Formation of agarwood from Aquilaria malaccensis in response to inoculation of local strains of Fusarium solani. Trees 31: 189-197

Henry G, Thonart P, Ongena M (2012) PAMPs, MAMPs, DAMPs and others: an update on the diversity of plant immunity elicitors. Biotechnol Agron Soc Environ 16:257-268

Komar TE, Wardani M, Hardjanti FI, Ramdhania N (2014) In situ and ex situ conservation of Aquilaria and Gyrinops: a review. ITTO CITES Phase II

Liao G, Dong W-H, Yang J-L, Li W, Wang J, Mei W-L, Dai H-F (2018) Monitoring the chemical profile in agarwood formation within one year and speculating on the biosynthesis of 2-(2phenylethyl)chromones. Molecules 23:1261

Liu Y et al (2013) Whole-tree agarwood-inducing technique: an efficient novel technique for producing high-quality agarwood in cultivated Aquilaria sinensis. Trees Mol 18:3086

Liu P, Zhang X, Yang Y, Sui C, Xu Y, Wei J (2019) Interxylary phloem and xylem rays are the structural foundation of agarwood resin formation in the stems of Aquilaria sinensis. Trees 33:533-542

Lv F et al (2019) Hydrogen peroxide burst triggers accumulation of jasmonates and salicylic acid inducing sesquiterpene biosynthesis in wounded Aquilaria sinesis. J Plant Physiol 234-235:167-175

Mohamed R, Jong PL, Zali MS (2010) Fungal diversity in wounded stems of Aquilaria malaccensis. Fungal Divers 43:67-74

Monggoot S, Popluechai S, Gentekaki E, Pripdeevech P (2017) Fungal endophytes: an alternative source for production of volatile compounds from agarwood oil of Aquilaria subintegra. Microb Ecol 74:54-61

Mulyaningsih T, Yamada I (2018) Three new species of Aquilaria (Thymelaeaceae) from Borneo Indonesia. AIP Confer Proceed 2023:020114

Naef R (2011) The volatile and semi-volatile constituents of agarwood, the infected heartwood of Aquilaria species: a review. Flavour Frag J 26:73-87

Nasution AA, Siregar UJ, Miftahudin, Turjaman M (2019) Identification of chemical compounds in agarwood-producing species Aquilaria malaccensis and Gyrinops versteegii. J Forest Res. https://doi.org/ 10.1007/s11676-018-00875-9

Naziz PS, Das R, Sen S (2019) The scent of stress: evidence from the unique fragrance of agarwood. Front Plant Sci 10:840

Novriyanti E, Santosa E (2011) The role of phenolics in agarwood formation of Aquilaria crassna Pierre ex Lecomte and Aquilaria microcarpa. Baill trees J Forest Res 2:101-113
Okudera Y, Ito M (2009) Production of agarwood fragrant constituents in Aquilaria calli and cell suspension cultures. Plant Biotechnol 26: 307-315

Pasaribu G, Waluyo TK, Pari G (2015) Analysis of chemical compounds distinguisher for agarwood qualities. J Forest Res 2:1-7

Pitzschke A, Schikora A, Hirt H (2009) MAPK cascade signalling networks in plant defence. Curr Opin Plant Biol 12:1-6

Premalatha K, Kalra A (2013) Molecular phylogenetic identification of endophytic fungi isolated from resinous and healthy wood of Aquilaria malaccensis, a red listed and highly exploited medicinal tree. Fungal Ecol 6:205-211

Rameau C, Bertheloot J, Leduc N, Andrieu B, Foucher F, Sakr S (2015) Multiple pathways regulate shoot branching. Front Plant Sci 5:741

Rasool S, Mohamed R (2016) Understanding agarwood formation and its challenges. In: Mohamed R (ed) Agarwood: science behind the fragrance. Springer Singapore, Singapore, pp 39-56

Santoso E, Irianto RS, Sitepu IR, Turjaman M (2011) Better inoculation engineering techniques. ITTO

Sen S, Dehingia M, Talukdar NC, Khan M (2017) Chemometric analysis reveals links in the formation of fragrant bio-molecules during agarwood (Aquilaria malaccensis) and fungal interactions. Sci Rep 7:44406

Shao H, Mei WL, Kong FD, Dong WH, Gai CJ, Li W, Zhu GP, Dai HF (2016) Sesquiterpenes of agarwood from Gyrinops salicifolia. Fitoterapia 113:182-187

Sitepu IR, Santoso E, Siran SA, Turjaman M (2011) Fragrant wood gaharu: when the wild can no longer provide. In: Production and Utilization Technology for Sustainable Development of Gaharu in Indonesia, Bogor, Indonesia

Subasinghe SMCUP, Hitihamu HID, KMEP F (2019) Use of two fungal species to induce agarwood resin formation in Gyrinops walla. $\mathrm{J}$ Forest Res 30:721-726

Susilo A, Kalima T, Santoso E (2014) Field guide to identification of agarwood producing tree Aquilaria spp. in Indonesia. ITTO CITES Phase II

Tamuli P, Boruah P, Nath SC, Leclercq P (2005) Essential oil of eaglewood tree: a product of pathogenesis. J Essent Oil Res 17: 601-604

Tan CS, Isa NM, Ismail I, Zainal Z (2019) Agarwood induction: current developments and future perspectives. Front Plant Sci 10:122

Thanh LV, Do TV, Son NH, Sato T, Kozan O (2015) Impacts of biological, chemical and mechanical treatments on sesquiterpene content in stems of planted Aquilaria crassna trees. Agrofor Syst 89:973981

Tian JJ, Gao XX, Zhang WM, Wang L, Qu LH (2013) Molecular identification of endophytic fungi from Aquilaria sinensis and artificial agarwood induced by pinholes-infusion technique. Afr J Biotechnol 12:3115-3131

Turjaman M, Hidayat A, Santoso E (2016) Development of agarwood induction technology using endophytic fungi. In: Mohamed R (ed) Agarwood: science behind the fragrance. Springer Singapore, Singapore, pp 57-71

Wang S, Yu Z, Wang C, Wu C, Guo P, Wei J (2018) Chemical constituents and pharmacological activity of agarwood and Aquilaria plants. Molecules 23:342

$\mathrm{Xu} \mathrm{Y}$ et al (2013) Identification of genes related to agarwood formation: transcriptome analysis of healthy and wounded tissues of Aquilaria sinensis. BMC Genomics 14:227

$\mathrm{Xu}$ Y-H et al (2016) Jasmonic acid is a crucial signal transducer in heat shock induced sesquiterpene formation in Aquilaria sinensis. Sci Rep 6:21843

Publisher's note Springer Nature remains neutral with regard to jurisdictional claims in published maps and institutional affiliations. 